\title{
Molecular characterization of Mycobacterium tuberculosis complex isolates from wild ungulates in south-central Spain
}

\author{
Christian GorTAZAR ${ }^{\text {a*}}$, Joaquín VICENTE ${ }^{\mathrm{a}}$, Sofia SAMPER ${ }^{\mathrm{b}}$, \\ Joseba M. GARRIDOc ${ }^{c}$, Isabel G. FERNÁNDEZ-DE-MERA ${ }^{a}$, Patricia GAVÍn ${ }^{b}$, \\ Ramón A. JUSTE ${ }^{\mathrm{c}}$, Carlos MARTíN ${ }^{\mathrm{d}}$, Pelayo ACEVEDO ${ }^{\mathrm{a}}$, \\ Manuel DE LA PUENTE ${ }^{\mathrm{a}}$, Ursula HÖFLE ${ }^{\mathrm{a}}$ \\ a Instituto de Investigación en Recursos Cinegéticos IREC (CSIC-UCLM-JCCM), \\ PO Box 535, 13080 Ciudad Real, Spain \\ b Servicio de Microbiología, Hospital Universitario Miguel Servet, Zaragoza, Spain \\ ${ }^{\mathrm{c}}$ Instituto Vasco de Investigación y Desarrollo Agrario NEIKER, Derio, Spain \\ ${ }^{\mathrm{d}}$ Departamento de Microbiología, Universidad de Zaragoza, Spain
}

(Received 28 February 2004; accepted 1 July 2004)

\begin{abstract}
The role of European wild ungulates in the epidemiology of tuberculosis (TB) is still under discussion. This study describes the geographical distribution and molecular typing of 77 Mycobacterium tuberculosis complex isolates belonging either to M. bovis or to M. caprae, cultivated from hunter harvested red deer (Cervus elaphus) and European wild boar (Sus scrofa) in 24 Spanish localities, and compares them with spoligotypes detected previously in humans, livestock or wild animals, as described in the literature. The distribution of the molecular type patterns suggests that the population of M. tuberculosis complex strains isolated from Spanish wild ungulates is spatially structured despite the lack of important geographical barriers and despite the increasingly frequent wildlife translocations. Red deer and the European wild boar can share the same molecular types in localities in which the M. tuberculosis complex was isolated from both species. Strains of bovine and caprine origin do circulate in the same local wildlife populations. Six out of 11 spoligotypes were similar to types described in human cases. The isolation of TB strains in fenced estates from wild animals that have not had contact with domestic livestock for at least the past two decades, strongly suggests that the $M$. tuberculosis complex is able to survive in these populations. Therefore, wildlife including cervids and the wild boar need to be considered in the epidemiology and control of tuberculosis.
\end{abstract}

epidemiology / reservoir / typing / tuberculosis / wildlife

\section{INTRODUCTION}

The Mycobacterium tuberculosis complex includes, among other members, the causative agent of bovine tuberculosis, Myco- bacterium bovis, and the causative agent of caprine tuberculosis, Mycobacterium caprae [3]. Worldwide, wildlife plays an important role in tuberculosis (TB) epidemiology [4, 25, 29]. In Europe, the most well known

\footnotetext{
* Corresponding author: christian.gortazar@uclm.es
} 
case is that of the badger (Meles meles) in the British islands, but TB cases have repeatedly been reported in other mammals, including wild and semi domestic (i.e. fenced-in) cervids [2, 22], and even the wild boar [26].

Nevertheless, the role of European wild ungulates in the epidemiology of TB is still under discussion. Due to the low frequency of detection of generalized tuberculosis in M. bovis infected European wild boars (Sus scrofa), and to the fact that these have only been detected in areas with infected cattle, Serraino et al. [26] hypothesized that wild boars are the end host for M. bovis infection, with little transmission possibilities to livestock and little relevance as a reservoir. In deer, some authors consider that bovine TB problems are mainly limited to farmed stock and that free-living deer are spill over hosts $[2,6]$. But evidence of the role of deer in TB epidemiology is increasing [22], especially since risk factors such as artificial feeding increase the intra-specific contact rates [25].

In the Iberian Peninsula, wild ungulate populations including the red deer (Cervus elaphus) and the European wild boar are expanding due to changes in land use and in human attitudes towards wildlife [10]. In southern and central Spain, where hunting is one of the most important sources of income for landowners, most of the wild ungulates are managed through fencing and feeding in order to increase the annual hunting harvest. Thus, high densities are not infrequent. Red deer population densities in hunting estates range from 36-98 deer per $\mathrm{km}^{2}$ [5], and wild boar densities may be as high as 16 per $\mathrm{km}^{2}$ [11].

In this context, it is not surprising that a number of cases of tuberculosis have already been diagnosed both in the Iberian red deer [3] and in the wild boar [3, 12, 19]. In Spain, previous research has already suggested inter-specific transmission of the M. tuberculosis complex between wild ungulates and domestic livestock [3, 19]. In addition, the manipulation of live or dead animals may eventually present a risk of this zoonosis for humans.

The present study describes the geographical distribution of the molecular (spacer oligonucleotide and MIRU-VNTR) types of 77 strains of $M$. tuberculosis complex cultivated from (apparently healthy) hunterharvested deer and boar, and compares them with spoligotypes detected previously in humans, livestock or wild animals, as described in the literature. We hypothesize that deer and wild boars share similar TB strains, and that these may be transmitted between wildlife, domestic livestock and humans. If so, the fact that domestic livestock has been absent from large parts of the study area for the last two decades, proves that wildlife alone is capable of maintaining the infection in the current epidemiological context.

\section{MATERIALS AND METHODS}

The survey was carried out in 24 sites, all placed within a $450000-\mathrm{km}^{2}$ rectangle in central and southern Spain. Geographical coordinates are from $37^{\circ} 13^{\prime} 48^{\prime \prime} \mathrm{N}$ to $39^{\circ}$ $31^{\prime} 43^{\prime \prime} \mathrm{N}$ in latitude and from $06^{\circ} 34^{\prime}$ ' $06^{\prime \prime}$ W to $2^{\circ} 25^{\prime} 54^{\prime \prime} \mathrm{W}$ in longitude (Fig. 1 ). The study sites were located in the provinces (regions) of Badajoz (Extremadura, $n=1$ ), Ciudad Real and Toledo (Castilla-La Mancha, $n=11$ ), and Córdoba, Jaén and Sevilla (Andalucía, $n=12$ ).

Wild ungulates, mainly European wild boar and red deer, are present throughout the hilly Mediterranean woodland habitats of the study area. Seventeen sampling sites were fenced hunting estates $(71 \%)$, while only seven were open ones. High wire fencing is a common management tool in the private and public hunting estates of the study area. Most of these fenced hunting estates are devoted exclusively to boar and deer hunting, and only a few of them do still maintain cattle. Nevertheless, cattle had been present in most estates until they became fenced, ten to twenty years ago. In 


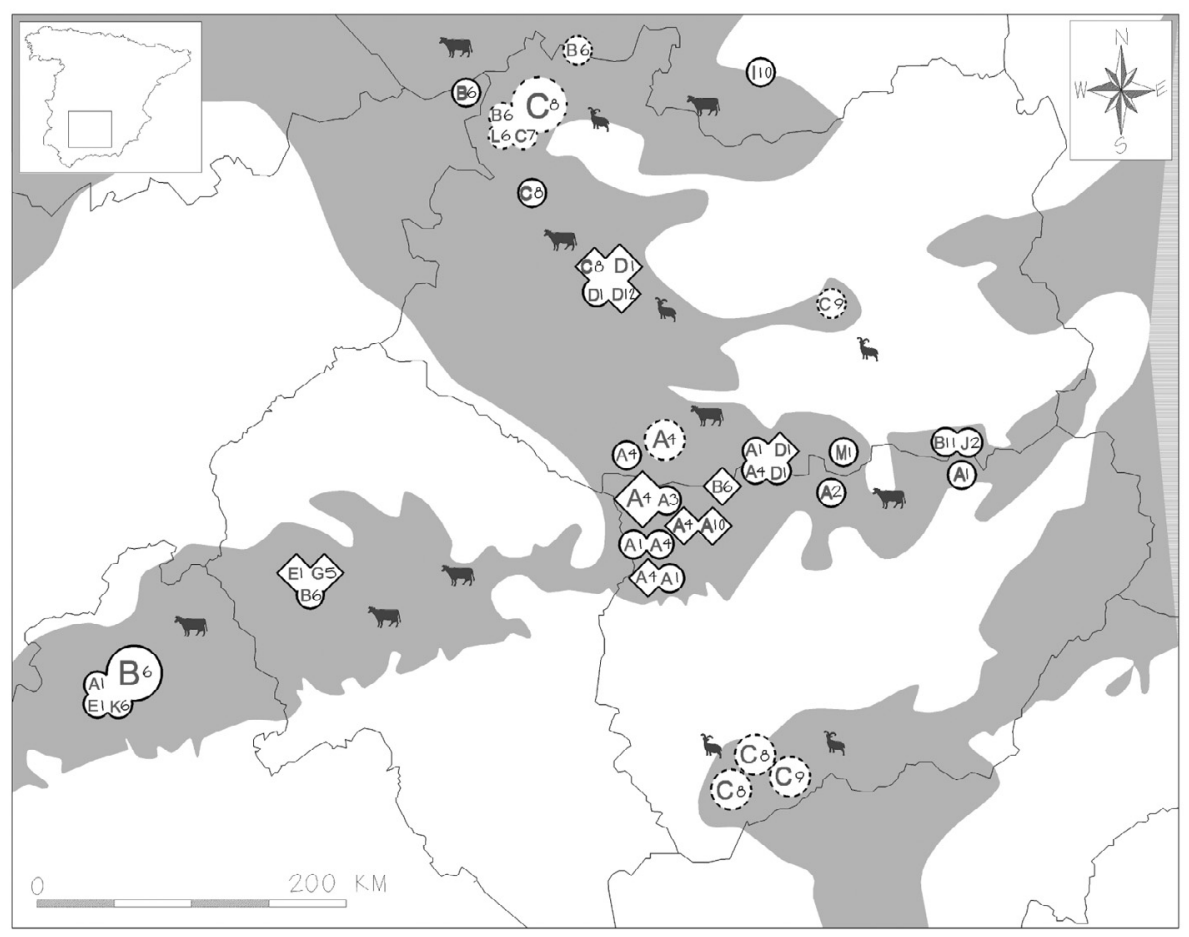

Figure 1. Spatial distribution of $77 M$. tuberculosis complex isolates from red deer $(\diamond)$ and European wild boar $(\bigcirc)$. Lines are province limits and the shaded area indicates woodland habitats. Letters indicate spoligotypes and the numbers the MIRU-VNTR types. The size of each sign means the number of isolates (small 1-3 isolates, medium 4-6 and large 7-9) of one spoligotype in a given sampling locality. Signs or groups of signs surrounded by a continuous line correspond to fenced estates, and those with dashed lines to non-fenced estates. Cattle and goat figures show the most common livestock species.

contrast, other uses, such as agriculture and sheep and goat breeding, are still frequent in the non-fenced sites.

The main rivers in the study area (Guadiana and Guadalquivir) can be crossed by wild ungulates at most times of the year, and tunnels or bridges allow wildlife to cross the few existing highroads. Thus (but for the fences), few barriers exist to animal movements, other than the open agro systems. Moreover, translocations of wild ungulates for hunting purposes are increasing in Spain, especially between fenced hunting estates or between game farms and hunting estates [14].
The samples were obtained from hunter harvested deer and wild boar during the $1999 / 2000$ to $2001 / 2002$ hunting seasons. We arbitrarily selected a random age and sex stratified subset of individuals of each species when the hunted animals exceeded our effective logistic capacity for sampling. A complete necropsy was performed in the field, with detailed macroscopic inspection of lymphnodes and abdominal and thoracic organs. This routine examination included parotidean, retropharyngeal and submandibular lymphnodes in the head; tracheobronchial and mediastinic lymphnodes and lungs in the thorax; and hepatic and mesenteric 
lymphnodes, ileocecal valve, kidneys, liver and spleen in the abdomen. Gross lesions in other locations were also recorded.

Pools of lymphnode samples were submitted to culture as described previously [1]. Briefly, two grams of sample were homogenized with $35 \mathrm{~mL}$ of a solution $(0.75 \%)$ of hexadecilpiridinium and left decontaminating for $18 \mathrm{~h}$. Each of four tubes of Coletsos medium (Bio-Mérieux, Marcyl'Étoile, France) was inoculated with three drops of the homogenate, incubated at $37^{\circ} \mathrm{C}$ and inspected weekly with the aid of a stereoscopic microscope for the presence of any growth. This set of strains comprised 19 M. tuberculosis complex isolates from the red deer and 58 isolates from the wild boar. After standard bacteriological identification, all 77 isolates were subjected to spoligotyping as described by [16] and each different spoligotype was arbitrarily named with a letter. All but one islolate $(n=76)$ were later typed by MIRU-VNTR, and each cluster was also arbitrarily numbered. The oligonucleotides used in the PCR corresponded to the flanking regions of the seven most polymorphic MIRU-VNTR loci identified in the M. tuberculosis $\mathrm{H} 37 \mathrm{Rv}$ genome (loci 4, 10, 16, 23, 26, 31 and 40). The numbers of MIRU per locus were calculated on the basis of conventions described in [28].

The spoligotypes were analysed with Bionumerics software (version 2.5; Applied Maths, Kortrijk, Belgium). A comparison of these spoligotypes with those previously reported from wildlife, domestic animals or humans, was done using figures contained in the references $[2,7-9,13,16,17,19-24$, 26, 29, 30].

GPS and GIS techniques have been used for locating the control points and for storing field data in mapping and analytical processes. The $M$. tuberculosis complex isolates were plotted on a map with SPANS version 7.1 (PCI Geomatics ${ }^{\circledR}$, Richmond Hill, Ontario, Canada) and IDRISI32 version I32.21 (The Clark labs. ${ }^{\circledR}$, Clark University, Worcester, MA, USA) Geographical Information System software in order to describe the distribution pattern of each spoligotype. Data on the spatial distribution of woodlands were modified from the CORINE database (Natlan, European Environment Agency, Copenhagen, Denmark) and its 44 classes were reclassified into two categories: woodland and cropland. We used the Chi square test to compare qualitative data [27].

\section{RESULTS}

Spoligotyping confirmed the M. tuberculosis complex identification of all 77 isolates and produced eleven different spoligotypes, of which three (27\% of the types and $4 \%$ of the isolates) were unique (Fig. 2 and Tab. I). Wild boar isolates belonged to ten different spoligotypes and red deer isolates belonged to six different spoligotypes. All spoligotypes identified in this study were characteristic of either M. bovis or $M$. caprae isolates. MIRU-VNTR typing further allowed to clasify the isolates into 12 clusters (Tab. II). When combined with the spoligotypes, MIRU subtyping divided the isolates into 19 groups. The three largest groups contained 16, 14, and 13 isolates, respectively (Tab. I).

Ten isolates came from localities with only one single isolate. Among the 14 localities with more than one isolate, four had only a single molecular type after combining spoligotyping and MIRU-VNTR typing $(29 \%)$. Five had two types (36\%), three had three types (21\%) and two had four different molecular types (14\%). Red deer and European wild boars share the same spoligotypes in 4 out of the 5 localities $(80 \%)$ in which the M. tuberculosis complex was isolated from both species. In two of them, MIRU-VNTR typing confirmed that the isolates from both species are similar, while in the other two, MIRU patterns differed between the wild boar and red deer strains (Fig. 1).

Twenty-two strains (29\%) shared the most common spoligotype. It was arbitrarily designated spoligotype A. The other major 


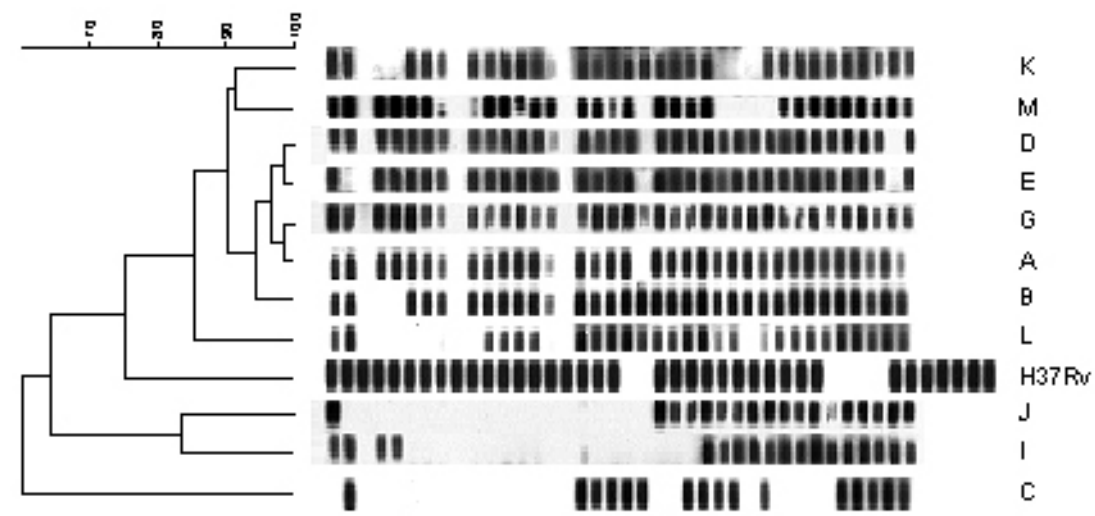

Figure 2. Spoligotype patterns identified in M. tuberculosis complex isolates from Spanish red deer and wild boars. Letter codes A to M were arbitrarily assigned.

spoligotypes were spoligotype $\mathrm{C}$, observed in 21 isolates (27\%); spoligotype B, observed in 14 isolates (18\%); and spoligotype $\mathrm{D}$, observed in 8 isolates $(10 \%)$. The remaining types grouped only five or fewer isolates (Tab. I).

Spoligotypes A and B have frequently been found in other studies, both in isolates from humans and in isolates from cattle. Type A is the most commonly found $M$. bovis spoligotype in human and cattle isolates in Spain, and it has also been reported in wild boar from Spain. It is the most common spoligotype among the deer isolates in this study ( 7 out of 19,37\%). To our knowledge, this is the first time both types are reported in deer (Tab. I).

Spoligotype A is the dominant type in central Sierra Morena, the center of the study area. This is a traditional cattle breeding area now mainly transformed into fenced estates devoted to deer and boar hunting. This type has not been found in the northern third of this area (Fig. 1). It is more frequent among isolates from fenced hunting estates $(n=19)$ than among those from open ones $\left(n=3\right.$; $\mathrm{Chi}^{2}=4.39,1$ d.f., $p<$ $0.05)$. MIRU typing shows that isolates belonging to the spoligotype A pattern can be divided into five different MIRU clus- ters. Cluster $\mathrm{C} 4$ was the dominant one, with 14 isolates from 7 sites, followed by cluster $\mathrm{C} 1$, with 5 isolates from 5 different sites. The remaining three groups contained one isolate each. In contrast, spoligotype B was found all over the study area, and all but one isolate belonged to the same MIRU cluster C6 (Tab. I).

Spoligotype $\mathrm{C}$ is characteristic of domestic goats (M. caprae), but has also been reported in cattle and in humans (Tab. I). In this study, type $\mathrm{C}$ was more often found in the wild boar ( 20 out of $58,34 \%$ ) than in deer ( 1 out of $19,5 \% ; \mathrm{Chi}^{2}=4.77,1$ d.f., $p<$ 0.05 ), and it was more frequent in open areas (19 out of 26 isolates, $73 \%$ ) than in fenced ones ( 3 out of $26,11 \%$; $\mathrm{Chi}^{2}=38.1$, 1 d.f., $p<0.001)$. In two cases, the "goat" spoligotype $\mathrm{C}$ was isolated from wild ungulates in areas where "bovine" spoligotypes had also been found (B and D). The other localities with $\mathrm{C}$ type isolates are placed in marginal and relatively isolated areas where big game is scarce and almost only represented by wild boars. MIRU typing distinguished 3 clusters within the $19 \mathrm{C}$-isolates. One had a singular MIRU pattern and was isolated in a fenced site with many different isolates. A second one was found in a single isolate site and in a site with 3 isolates that all shared the same MIRU pattern. 
Table I. Host species, number of isolates and number of sampling sites for each spoligotype pattern identified in deer and the wild boar from Spain. For each spoligotype pattern, the number of isolates and sites for the identified MIRU-VNTR clusters are shown, as well as the relationships between the identified spoligotypes and those of isolates from humans and from livestock already described in the literature.

\begin{tabular}{|c|c|c|c|c|}
\hline Spoligotype & No. of hosts (sites) & $\begin{array}{l}\text { Reported host species } \\
\quad \text { (reference) }\end{array}$ & Country & $\begin{array}{c}\text { VNTR-MIRU } \\
\text { cluster (isolates, sites) }\end{array}$ \\
\hline $\begin{array}{l}\text { A } \\
\text { (22 isolates) }\end{array}$ & $\begin{array}{l}15 \text { wild boar (9) } \\
7 \text { red deer (3) } \\
\text { Total sites: } 10\end{array}$ & $\begin{array}{c}\text { Cattle [2] } \\
\text { Human [13] } \\
\text { Pig [19] } \\
\text { Wild boar [2] }\end{array}$ & Worldwide & $\begin{array}{l}\text { C1 (5 isolates, } 5 \text { sites }) \\
\text { C2 (1 isolate, } 1 \text { site }) \\
\text { C3 (1 isolate, } 1 \text { site }) \\
\text { C4 (14 isolates, } 7 \text { sites }) \\
\text { C10 (1 isolate, } 1 \text { site })\end{array}$ \\
\hline $\begin{array}{l}\text { B } \\
\text { (14 isolates) }\end{array}$ & $\begin{array}{l}13 \text { wild boar (6) } \\
1 \text { red deer } \\
\text { Total sites: } 7\end{array}$ & $\begin{array}{c}\text { Cattle }[2,13] \\
\text { Human }[13] \\
\text { Wild boar [26] }\end{array}$ & Worldwide & $\begin{array}{c}\text { C6 (13 isolates, } 6 \text { sites) } \\
\text { C11 (1 isolate, } 1 \text { site) }\end{array}$ \\
\hline $\begin{array}{l}\text { C } \\
\text { (21 isolates) }\end{array}$ & $\begin{array}{l}20 \text { wild boar (6) } \\
1 \text { red deer } \\
\text { Total sites: } 7 \text { (5) }\end{array}$ & $\begin{array}{c}\text { Cattle (own unpublished } \\
\text { data) } \\
\text { Goat [13] } \\
\text { Human [13] }\end{array}$ & Spain & $\begin{array}{c}\text { C8 (16 isolates, } 5 \text { sites }) \\
\text { C9 (4 isolates, } 2 \text { sites }) \\
\text { C7 (1 isolate, } 1 \text { site })\end{array}$ \\
\hline $\begin{array}{l}\text { D } \\
\text { (8 isolates) }\end{array}$ & $\begin{array}{l}2 \text { wild boar (2) } \\
6 \text { red deer }(2) \\
\text { Total sites: } 2\end{array}$ & $\begin{array}{c}\text { Cattle [2] } \\
\text { Llama (own } \\
\text { unpublished data) }\end{array}$ & Worldwide & $\begin{array}{l}\text { C1 (7 isolates, } 2 \text { sites) } \\
\text { C12 (1 isolate, } 1 \text { site) }\end{array}$ \\
\hline $\begin{array}{l}\mathrm{E} \\
\text { (4 isolates) }\end{array}$ & $\begin{array}{l}2 \text { wild boar } \\
2 \text { red deer } \\
\text { Total sites: } 2\end{array}$ & Human $[16,30]$ & Spain & $\mathrm{C} 1$ (4 isolates, 2 sites) \\
\hline $\begin{array}{l}\mathrm{G} \\
\text { (2 isolates) }\end{array}$ & $\begin{array}{l}2 \text { red deer } \\
\text { Total sites: } 1\end{array}$ & $\begin{array}{c}\text { Cattle }[13,26] \\
\text { Human }[13] \\
\text { Wild boar [26] }\end{array}$ & $\begin{array}{l}\text { Worldwide } \\
\text { (BCG type) }\end{array}$ & C5 (2 isolates, 1 site) \\
\hline $\begin{array}{l}\text { I } \\
(1 \text { isolate })\end{array}$ & $\begin{array}{l}1 \text { wild boar } \\
\text { Total sites: } 1\end{array}$ & & Unique & C10 ( 1 isolate, 1 site) \\
\hline $\begin{array}{l}\mathbf{J} \\
\text { (1 isolate) }\end{array}$ & $\begin{array}{l}1 \text { wild boar } \\
\text { Total sites: } 1\end{array}$ & $\begin{array}{c}\text { No species specified } \\
{[30]}\end{array}$ & Spain & C2 (1 isolate, 1 site) \\
\hline $\begin{array}{l}\mathrm{K} \\
(1 \text { isolate })\end{array}$ & $\begin{array}{l}1 \text { wild boar } \\
\text { Total sites: } 1\end{array}$ & & Unique & C6 (1 isolate, 1 site) \\
\hline $\begin{array}{l}\mathrm{L} \\
\text { (2 isolates) }\end{array}$ & $\begin{array}{l}2 \text { wild boar } \\
\text { Total sites: } 1\end{array}$ & & Unique & C6 (1 isolates, 1 site) \\
\hline $\begin{array}{l}\text { M } \\
\text { (1 isolate) }\end{array}$ & $\begin{array}{l}1 \text { wild boar } \\
\text { Total sites: } 1\end{array}$ & $\begin{array}{c}\text { Cattle [2] } \\
\text { Human [13] } \\
\text { Wild boar [19] }\end{array}$ & Spain & $\mathrm{C} 1$ (1 isolate, 1 site) \\
\hline
\end{tabular}

Total: 58 wild boar isolates; 19 red deer isolates. Positive sites: 24; number of spoligotypes: 11; MIRUVNTR typing further divided the 11 spoligotypes into 19 subtypes.

Spoligotypes D, G and $\mathrm{M}$ are also common in cattle. Strains with the spoligotype $G$ and $\mathrm{M}$ have been found in humans. Type $\mathrm{G}$ is identical to the spoligotype pattern for $M$. bovis $\mathrm{BCG}$ and has been reported in wild boars from Italy, while type $\mathrm{M}$ has recently been found in wild boars from Spain (Tab. I). MIRU typing showed that both type $\mathrm{G}$ isolates have the same MIRU-pattern as BCG-Japan. 
Table II. Patterns identified in this study using the seven most polymorphic MIRU-VNTR loci identified in the M. tuberculosis H37Rv genome.

\begin{tabular}{lccccccc}
\hline Cluster & MIRU 4 & MIRU 10 & MIRU 16 & MIRU 23 & MIRU 26 & MIRU 31 & MIRU 40 \\
\hline H37Rv & 3 & 3 & 2 & 6 & 3 & 3 & 1 \\
C1 & 3 & 2 & 3 & 4 & 5 & 3 & 2 \\
C2 & 3 & 2 & 3 & 4 & 6 & 3 & 2 \\
C3 & 3 & 3 & 3 & 4 & 5 & 3 & 2 \\
C4 & 4 & 2 & 3 & 4 & 5 & 3 & 2 \\
C5 & 3 & 2 & 3 & 4 & 5 & 3 & 1 \\
C6 & 3 & 2 & 3 & 4 & 4 & 3 & 2 \\
C7 & 4 & 3 & 4 & 4 & 4 & 5 & 2 \\
C8 & 4 & 3 & 4 & 4 & 5 & 5 & 2 \\
C9 & 4 & 3 & 4 & 4 & 5 & 2 & 2 \\
C10 & 3 & 2 & 3 & 4 & 2 & 3 & 2 \\
C11 & 3 & 2 & 2 & 4 & 4 & 3 & 2 \\
C12 & 3 & 2 & 3 & 4 & 1 & 3 & 2 \\
\hline
\end{tabular}

Spoligotypes E and $\mathrm{J}$ were far less common (Tab. I). In the present study, type E was found both in deer and wild boars, and type $\mathrm{J}$ only in one wild boar. All type E isolates came from the provinces of Sevilla and Córdoba, in the south-western part of the study area. MIRU typing showed identical E-isolate patterns in these two sites. In a hospital within one of these provinces, two human cases of $M$. bovis infection with the same spoligotype pattern have recently been reported.

All three unique spoligotypes, named I, $\mathrm{K}$ and L respectively, belonged to wild boar isolates. The affected wild boars had been shot in the northern and south-western limits of the study area. Type I was found in an estate known to import animals from Central and Eastern Europe. This type was sent to be compared with the patterns included in the international database of spoligopatterns in the National Institute of Public Health and Environmental Protection (Bilthoven, The Netherlands) consisting in 3108 patterns originating from 51 countries. Type I was unique among the patterns in this database. MIRU typing confirmed that isolates with spoligotypes I and L were different from the other isolates described in this study (Tab. I).

\section{DISCUSSION}

The diversity of spoligotype patterns found in the present study (11 types among 77 isolates) was similar to those found by other authors (e.g. [2], who found 24 types among 182 isolates; [8], 35 types among 273 isolates; and [26], 8 among 30). The proportion of unique types ( 3 out of 11) was higher than that reported by Zumárraga et al. ([29], 22 out of 224). MIRU-VNTR typing showed that the most common spoligotypes can be subdivided into different groups. This confirms that it is desirable to combine spoligotyping with differentiation using other molecular tools ([8], but see [26]).

The distribution of typing patterns suggests that the population of M. tuberculosis complex strains isolated from Spanish wild ungulates is spatially structured despite the lack of important geographical barriers and despite the increasingly frequent translocations of wild ungulates. This is especially evident in the case of the most common spoligotype A that has almost exclusively been found in central Sierra Morena (even if in different MIRU clusters). One possible explanation is that the typical bovine strains currently isolated from wild ungulates in the hunting estates from Sierra Morena are 
derived mainly from the cattle that had been present in most of the sampling sites until they became fenced. In contrast, domestic goats are still frequent in most of the few non-fenced sampling sites. There, spoligotype C (typically a goat-TB strain) may be transmitted between goats and wildlife. Nevertheless, the results also show that strains of bovine and caprine origin do circulate in the same local wildlife populations. The presence of $M$. caprae strains in free-living deer has already been reported in Austria, with a slightly different spoligotype pattern [22].

The identification of hunting estates with up to four different molecular types of the M. tuberculosis complex is consistent with the hypothesis that translocations of wild ungulates may change the current distribution map of tuberculosis strains, and it highlights the disease risks that occur if appropriate veterinary control measures are not implemented [14].

In the future, it will be interesting to investigate the causes of the local dominance of a particular type, to monitor the changes of this situation in time, to identify eventual epidemiological differences, and to study any differences between the main types in the associated pathological lesions. Molecular tools will also be useful if vaccination of wildlife with BCG strains is eventually approved.

The results show that in Spain, the European wild boar and red deer can share the same M. tuberculosis complex types. Moreover, the comparison of the spoligotype patterns obtained with those described in the literature suggests that the spoligotypes from wildlife isolates are similar to those of domestic livestock, and not only to those of cattle but also to those of goats and pigs. Finally, several spoligotypes (6 out of 11) are also similar to those described in human cases. This suggests that hunters, wildlife managers or game-meat consumers may be at risk of getting infected.

Furthermore, the isolation of TB strains in fenced estates from wild animals that for two decades had no contact with domestic livestock, strongly suggests that the $M$. tuberculosis complex is able to survive in these wildlife populations, at least under the particular conditions of dry woodland habitats intensively managed for game production. Therefore in Spain, and probably also in other Mediterranean landscapes, not only domestic livestock, but also wildlife including cervids and wild boar, need to be considered in the epidemiology of tuberculosis. In this sense, the wild boar appears to be a better tracer species than cervids, and this could be linked to its feeding behaviour (scavenging and soil rooting). In fact, feral pigs are used as sentinels in TB surveillance (e.g. [18]).

Among wild ungulates, the European wild boar is ubiquitous and is expanding its geographical range [10], has a high mobility [15], and is able to under cross the fences of hunting estates. Even if only a low proportion of the infected wild boars have generalised lesions $[12,26]$, shedding of mycobacteria is likely to occur in the saliva even in individuals with lesions restricted to the mandibular lymph nodes [12]. Thus, more attention should be devoted to the ecology and pathology of this wild ungulate in the near future.

Changes in land use, but in particular the increasingly artificial management of game species with fencing, feeding and translocation of wildlife, needs to be regulated and taken into account when TB eradication programs are implemented. Considering the high densities of wild ungulates that currently are maintained in many hunting estates, and the lack of knowledge on the risk factors that affect TB prevalence in Spanish wildlife, more research is urgently needed.

\section{ACKNOWLEDGEMENTS}

We gratefully acknowledge Kristin Kremer and Dick van Soolingen for comparing spoligotyping, and Diego Villanúa and the many students that assisted us in the field and in the laboratory. We also thank the Associate Editor 
and two anonymous referees for their comments. The study was supported by project AGL20013947, Ministerio de Ciencia y Tecnología and FEDER. A wider study on wildlife TB is supported by INIA, MCYT RTA03-074-C2-2, and Grupo Santander. This is a contribution to the agreement between Yolanda Fierro and Universidad de Castilla - La Mancha. Joaquín Vicente had a grant from Junta de Comunidades de Castilla - La Mancha.

\section{REFERENCES}

[1] Aduriz J.J., Juste R.A., Cortabarria N., Lack of mycobactin dependence of mycobacteria isolated on Middlebrook 7H11 from clinical cases of ovine paratuberculosis, Vet. Microbiol. 45 (1995) 211-217.

[2] Aranaz A., Liébana E., Mateos A., Domínguez L., Vidal D., Domingo M., Gonzolez O., Rodríguez-Ferri E.F., Bunschoten A.E., Van Embden J.D., Cousins D., Spacer oligonucleotide typing of Mycobacterium bovis strains from cattle and other animals: a tool for studying epidemiological of tuberculosis, J. Clin. Microbiol. 34 (1996) 2734-2740.

[3] Aranaz A., Cousins D., Mateos A., Domínguez L., Elevation of Mycobacterium tuberculosis subsp. caprae Aranaz et al. 1999 to species rank as Mycobacterium caprae comb. nov., sp. nov., Int. J. Syst. Evol. Microbiol. 53 (2003) 1785-1789.

[4] Artois M., Delahay R., Guberti V., Control of infectious diseases of wildlife in Europe, Vet. J. 162 (2001) 141-152.

[5] Azorit C., Analla M., Carrasco R., MuñozCobo J., Influence of age and environment on antler traits in Spanish red deer (Cervus elaphus hispanicus), Z. Jagdwiss. 48 (2002) 137144.

[6] Clifton-Hadley R.S., Wilesmith J.W., Tuberculosis in deer: a review, Vet. Rec. 129 (1991) 5-12.

[7] Costello E., O’Grady D., Flynn O., O’Brien R., Rogers M., Quigley F., Egan J., Griffin J., Study of restriction fragment length polymorphism analysis and spoligotyping for epidemiological investigation of Mycobacterium bovis infection, J. Clin. Microbiol. 37 (1999) 3217-3222.

[8] Cousins D.V., Skuce R.A., Kazwala R.R., van Embden J.D., Towards a standardized approach to DNA fingerprinting of Mycobacterium bovis, International Union Against Tuberculosis and Lung Disease, Tuberculosis in Ani- mals Subsection, Int. J. Tuberc. Lung. Dis. 2 (1998) 471-478.

[9] Goguet de la Salmoniere Y.O., Li H.M., Torrea G., Bunschoten A., van Embden J.D., Icquel G., Evaluation of spoligotyping in a study of the transmission of Mycobacterium tuberculosis, J. Clin. Microbiol. 35 (1997) 2210-2214.

[10] Gortazar C., Herrero J., Villafuerte R., Marco J., Historical examination of the status of large mammals in Aragon, Spain, Mammalia 64 (2000) 411-422.

[11] Gortazar C., Vicente J., Fierro Y., Leon L., Cubero M.J., Gonzalez M., Natural Aujeszky's disease in a Spanish wild boar population, Ann. NY Acad. Sci. 969 (2002) 210-212.

[12] Gortazar C., Vicente J., Gavier-Widen D., Pathology of bovine tuberculosis in the European wild boar, Vet. Rec. 152 (2003) 779780.

[13] Gutiérrez M., Samper S., Jimenez M.S., van Embden J.D., Marín J.F., Martín C., Identification by spoligotyping of a caprine genotype in Mycobacterium bovis strains causing human tuberculosis, J. Clin. Microbiol. 35 (1997) 3328-3330.

[14] Höfle U., Vicente J., Nagore D., Hurtado A., Peña A., de la Fuente J., Gortazar C., The risks of translocating wildlife: pathogenic infection with Theileria sp. and Elaeophora elaphi in an imported red deer, Vet. Parasitol. (2004) DOI: 10.1016/j.vetpar.2004.07.026.

[15] Janeau G., Cousse S., Cargnelutti B., Spitz F.T.I., Role of daily movements in the sociospatial organization of wild boar populations (Sus scrofa), Rev. Ecol. Terre Vie 50 (1995) 35-48.

[16] Kamerbeek J., Schouls L., Kolk A., van Agterveld M., van Soolingen D., Kuijper S., Bunschoten A., Molhuizen H., Shaw R., Goyal M., van Embden J., Simultaneous detection and strain differentiation of $\mathrm{Myco}$ bacterium tuberculosis for diagnosis and epidemiology, J. Clin. Microbiol. 35 (1997) 907914.

[17] Milián-Suazo F., Banda-Ruiz V., RamírezCasillas C., Arriaga-Díaz C., Genotyping of Mycobacterium bovis by geographic location within Mexico, Prev. Vet. Med. 55 (2002) 255264.

[18] Nugent G., Whitford J., Young N., Use of released pigs as sentinels for Mycobacterium bovis, J. Wildl. Dis. 38 (2002) 665-677.

[19] Parra A., Fernández-Llario P., Tato A., Larrasa J., García A., Alonso J.M., Hermoso 
de Mendoza M., Hermoso de Mendoza J., Epidemiology of Mycobacterium bovis infections of pigs and wild boars using a molecular approach, Vet. Microbiol. 97 (2003) 123-133.

[20] Pavlik I., Dvorska L., Bartos M., Parmova I., Melicharek I., Jesenka A., Havelkova M., Slorarek M., Putova I., Martin G., Erler W., Kremer K.D., Van Soolingen A., Molecular epidemiology of bovine tuberculosis in Czech Republic and Slovakia in the period 19652001 studied by spoligotyping, Vet. Med. Czech. 47 (2002) 181-194.

[21] Perumaalla V.S., Adams L.G., Payeur J., Baca D., Ficht T.A., Molecular fingerprinting confirms extensive cow-to-cow intra-herd transmission of a single Mycobacterium bovis strain, Vet. Microbiol. 70 (1999) 269-276.

[22] Prodinger W.M., Eigentler A., Allerberger F., Schonbauer M., Glawischnig W., Infection of red deer, cattle, and humans with Mycobacterium bovis subsp. caprae in Western Austria, J. Clin. Microbiol. 40 (2002) 2270-2272.

[23] Roring S., Brittain D., Bunschoten A.E., Hughes M.S., Skuce R.A., van Embden J.D., Neill S.D., Spacer oligotyping of Mycobacterium bovis isolates compared to typing by restriction fragment length polymorphism using PGRS, DR and IS6110 probes, Vet. Microbiol. 61 (1998) 111-120.

[24] Samper S., Martín C., Pinedo A., Rivero A., Blazquez J., Baquero F., van Soolingen D., van Embden J., Transmission between HIVinfected patients of multidrug-resistant tuberculosis caused by Mycobacterium bovis, AIDS 11 (1997) 1237-1242.
[25] Schmitt S.M., O’Brien D.J., Bruning-Fann C.S., Fitzgerald S.D., Bovine tuberculosis in Michigan wildlife and livestock, Ann. NY Acad. Sci. 969 (2002) 262-268.

[26] Serraino A., Marchetti G., Sanguinetti V., Rossi M.C., Zanoni R.C., Catozzi L., Bandera A., Dini W., Mignone W., Franzetti F., Gori A., Monitoring of transmission of tuberculosis between wild boars and cattle: genotypical analysis of strains by molecular epidemiology techniques, J. Clin. Microbiol. 37 (1999) 2766-2771.

[27] Siegel S., Estadística no paramétrica, Ed. Trillas S.A., México D.F., 1970.

[28] Supply P., Lesjean S., Savine E., Kremer K., van Soolingen D., Locht C., Automated highthroughput genotyping for study of global epidemiology of Mycobacterium tuberculosis based on mycobacterial interspersed repetitive units, J. Clin. Microbiol. 39 (2001) 35633571 .

[29] Zumarraga M.J., Bernardelli A., Bastida R., Quse V., Loureiro J., Cataldi A., Bigi F., Alito A., Castro Ramos M., Samper S., Otal I., Martín C., Romano M.I., Molecular characterization of mycobacteria isolates from seals, Microbiology 145 (1999) 2519-2526.

[30] Zumarraga M.J., Martín C., Samper S., Alito A., Latini O., Bigi F., Roxo E., Cicuta M.E., Errico F., Ramos M.C., Cataldi A., van Soolingen D., Romano M.I., Usefulness of spoligotyping in molecular epidemiology of Mycobacterium bovis-related infections in South America, J. Clin. Microbiol. 37 (1999) 296-303. 